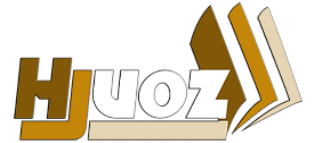

hjuoz.uoz.edu.krd p-ISSN: 2410-7557 e-ISSN: 2518-5128
كُوَفارا زانستيّن مروّاقايهتى يا زانكوّيا زاخوّ

مجلة العلوم الانسانية لجامعة زاخو

Humanities Journal of University of Zakho (HJUOZ)

Vol. 5, No. 1, pp. 156-166, March-2017

\title{
المساجد والتكايا والكنائس والمدارس في بدليس في القرنين السادس عشر والسابع عشر
}

\author{
صلاح محمد سليم محمود 1 و ماجد محمد يونس2 \\ 1قسم الاجتماعيات، فاكولتي التربية الاساسية، جامعة دهوك، أقليم كوردستان - العراق. \\ 2قسم التاريخ، فاكولتي العلوم الانسانية، جامعة زاخو، أقليم كوردستان - العراق.
}

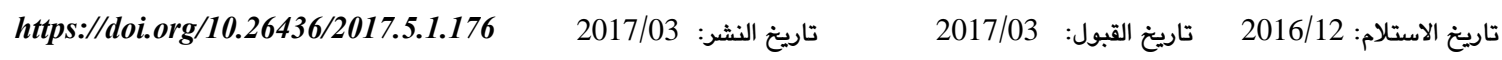

الملخص:

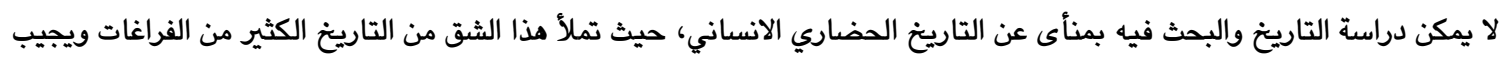
على الكثير من التساؤولات التي تنقص اليها الفروع الاخرى من التاريخ، وهي في الكثير من الاحيان لا تحظى بالاممية التي تستحقها

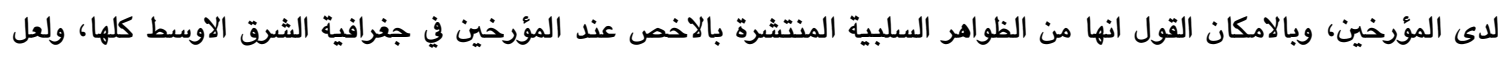

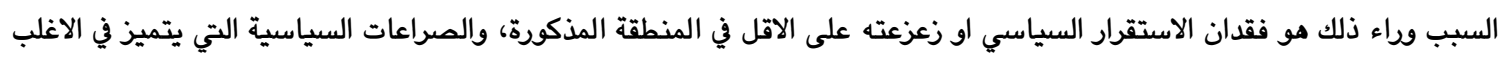
منها باللجوء الى العنف لتصفية المخاصمين، والتي ادى بدوره الى الاهتمام المتزايد بالتاريخ السياسي واهمال الجوانب الاخرى، كما

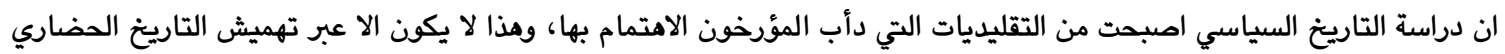

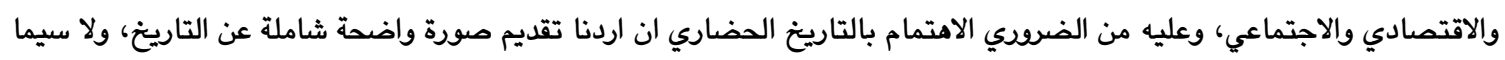

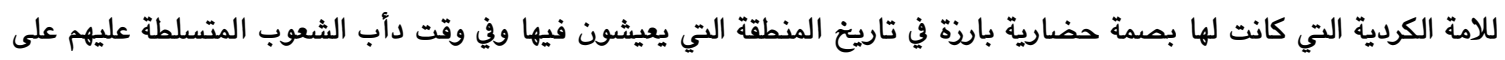

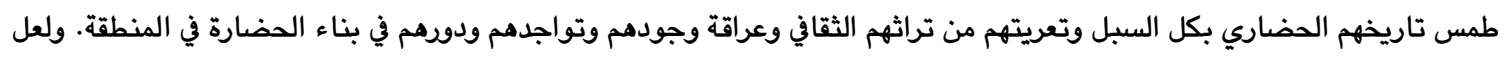

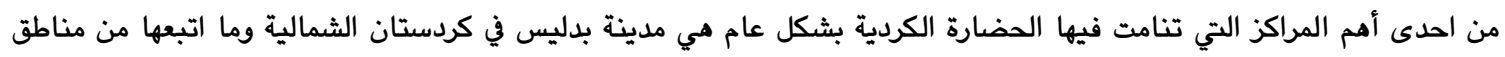

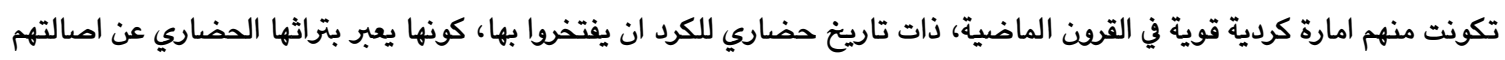

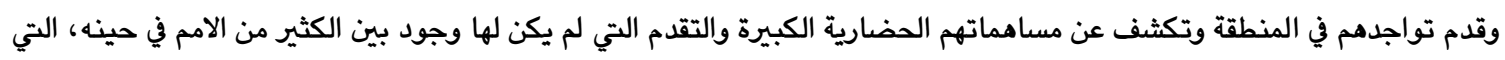
ادى في الكثير من الاحيان الى ان يضرب بها حتى السياح الاوربيون المثل لقياس الجمال والتطور الفكري والعلمي والحضاري الحاصل

الكلمات الدالة: المساجد، بدليس، الكنائس، المدارس، التكايا.

المثيل في كردستان رغم ما تم تهديمه بسبب الطقس وعوامل التعرية وعامل الزمن وكذلك ما تم تخريبه اثناء الاحتلال الروسي لها في الحرب تلمبات

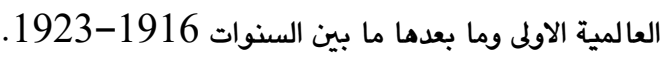

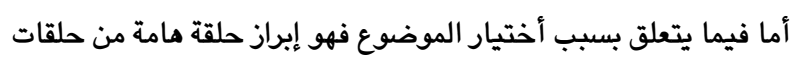

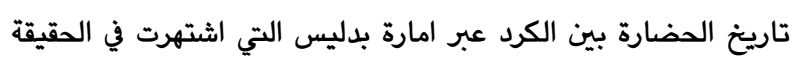

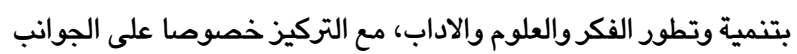
العمرانية فيها متمثلة بالمساجد والتكايا والكنائس والمدارس، وقد القد اختير القرنين السادس عشر والسابع عشر من الزمن كونهما القرنان الذهبيان التي عبرتها امارة بدليس في الصعد كافة ومنها التقدم

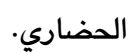
يتكون البحث من اربعة اقسام، يتمحور القسم الاول منها بتعريف اهم

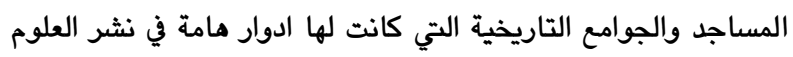

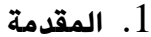

يعتبر امارة بدليس من المدن والمناطق التي حافظت على عتاقتها والملامح التاريخية والحضارية للقرون الغابرة في كردستان الشمالية، وبالامكان ويسهولة تخيل ورسم ماضيها والادوار التي مرت بها من خلال النظر في الاثار التي خلفتها امم تناويت على الحكم والسيطرة عليها لفترات زمنية، بغض النظر عن البصمة الحضارية الاكبر لاصحابها الكرد

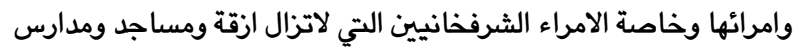
وجسور وقناطر وحمامات بدليس شهودا على ذلك شاخصة للابصار،

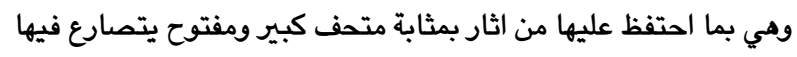
اثارها من مناراة المساجد وصلبان الكنائس واقواس الجسور والقناطر واحجار حيطان الحمامات لاظهار جمالية طرزها المعمارية واسرار هندستها الابداعية، موحية بانها كانت مركزا لنهضة حضارية نادرة 
الجنوبي فهناك شباك صغير الى يسار المحراب واخرى الى يمينها، وهي تحتوي اجمالا على 10 شبابيك، لا يمتلك الجامع باحة مفتوحة او حوش ، يبلغ مجموع الشبابيك فيها 10 شبابيك مقوسة، وللجامع قبة بـابة ليست بكبيرة يبلغ قطرها حوال 7 - 8 امتار، مساحتها في الداخل يبلغ 13.80 x 19.80 م، وهو بذلك يتسع لحوالي اكثر من 275 موره 300 مصليا 8، وهو يعبر عن فن معماري حجري متقدم في القرن الـ

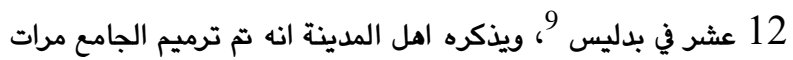

2.2 - (امده عالمدار:

من المساجد التاريخية في بدليس، يقع في مركز المدينة في الجهة الجنوبية، بني الجامع سنة 1150م، وفي سنة 1651-1652 ثم ترميمها لاول مرة، وفي ثمانينات القرن الماضي تم بناء منارة للمسجد

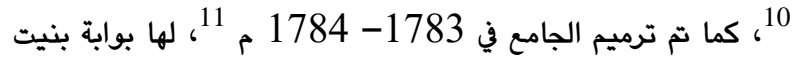
بالحجر الاحمر وقطع من الحجر الاصفر بثلاث اقواس متداخلة بشكل هندسي جميل وجذاب، كما ان بناءها من الحجر الاحمر المقطوع، وللجامع حوش غير منتظم، يرفع سقف حرمها اربعة اعمدة في شرق وغرب الحرم، كما يحتوي الجامع على مقبرة وقبر فيض الله الانصاري الذي لقب بعالمدار لانه كان يحمل علم الجيش الاسلامي اثناء الفتح، اخ الصحابي ابي ايوب الانصاري، وللجامع منارة يقدر طولها حوالي . $25-20$

3.2 يقع هذا الجامع في مركز بدليس، من الجوامع الصغيرة، مستطيل الشكل، بني من الحجر الاحمر البدليسي، لها منارة، وحسب نقوش على حائط للجامع فان تاريخ بنائه يعود لسنة 1444 م، وقد بني من قبل لتبل الامير محمد ابن الامير ابراهيم، والظاهر عليها انها تعرضت للترميم

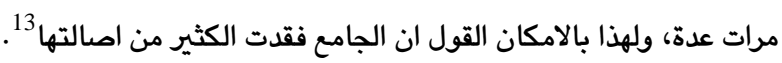
4.2. قزل مسجد (المسجد الاحمر): يقع مذا المسجد في في مركز بدليس، في حي سمي باسمه، كان ديرا ارمنيا قبل الفتح الاسلامي للمنطقة والتي كانت في سنة 640-641 مئمي 14، لايعرف بالضبط تاريخ تشيد هذا الجامع، ولكن جدد بنائها ورممت فئ فئ سنة 913 هـ، وهذا ما كتب حفرا على لوحة حجرية في اعلى باب الجامع، والذي يصادف سنة 1507 م، كما اعيدت ترميمها من قبل

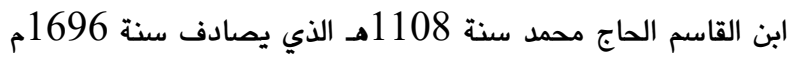
وهذا ايضا محفور في لوحة حجرية في اعلى لوحة الترميم الاولى، بنيت

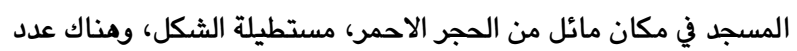

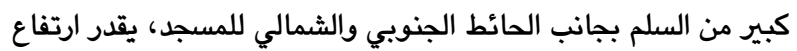
الحائط الغربي للمسجد والذي يعتبر اكثر ارتفاعا من الحيطان الاخرى بحوالي 18- 20 م، ويعتبر هذا الحائط المصدر الرئيسي للانارة في المسجد اذ يحتوي على 4 شبابيك مريعة الشكل و8 شبابيك مقوسة وعلى كل شباكين حواجب محفورة من الحجر تعطيها جمالية خاصة،
والمعارف في بدليس من حيث الجانب المعماري بالدرجة الاولى، اما القسم الثاني فيتناول التكايا والزوايا الصوفية التي اهتمت بنشر الافكار الدينية الصوفية في الامارة من جهة اضافة الى تقديم العون والمساعدة لعابري السبيل من الغرباء في الاراضي التي كانت تابعة لامارة بدليس، في حين يتطرق القسم الثالث من الدراسة بالكنائس التاريخية المنتشرة في ربوع الامارة لتعبر عن الاندماج التاريخي الاجتماعي والحضاري بين الكرد وقوميات من اديان اخرى عاشوا بينهم، ومن جانب ثان بيان قدم انتشار المسيحية في كردستان وما يجلبه الديانات من تسامح واحداث تغيرات في مسيرة الانسان الحضارية، وفي القسم الرابع والاخير تم التطرق الى المدارس المشهورة في امارة بدليس والتي كانت بحق منابع اشعاع حضاري تباهت بها الكرد في تلك الحقب من التاريخ. اما بخصوص مصادر هذه الدراسة فيعد الزيارات الميدانية للباحث للمعالم الحضارية المذكورة اممها والمصدر الرئيسي للحصول على المعلومة التاريخية، لسبب وجيه وهو قلة المصادر المكتوية عن الجوانب الحضارية كما سبقت الاثارة الى ذلك، لذا حاول الباحث تقديم تلك المعالم بالاعتماد على رؤيتها عن قرب وتحديد موقعها، ودراسة ما تبقت منها، وكذلك تقديم الارقام التي تخص الجوانب الهندسية من العمارة، وسماتها وخصائصها المعمارية وابراز امميتها التاريخية والحضارية، اضافة الى مصادر اخرى رفد الباحث بمعلومات مهمة اكملت رسم الصورة الحضارية للمعالم العمرانية المذكورة، وهي مثبتة في قائمة الهوامش والمصادر.

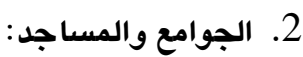

يعد المساجد من احدى اهم الاثارات الدالة على قدم الحضارة في بدليس، وقد انتشرت فيها العشرات منها في ارجائها والتي تثبت ارتباط اهلها العميق بالاسلام ومبادئه، حيث كانت المساجد مراكز للتعبد والدعوة وانتشار وتعريف الديانة الاسلامية، بالاضافة الى كونها اعتبرت مراكز هامة لنشر العلم وتكوين العلماء والفقهاء والمثقفين، ولعل من امم تلك المساجد والجوامع التي انشأت في بدليس في حقب تاريخية مختلفة والتي كانت ذا ادوار مامة هي : 1.2 اولو جامي(الجامع الكبير) (1): يعتبر من المعالم الاثرية ذات الاممية في بدليس (2)، يقع في منطقة

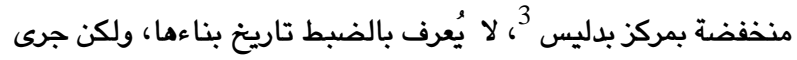

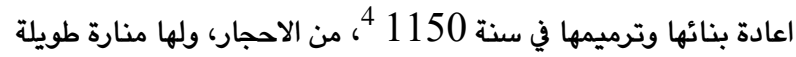
تقدر بـ ما بين 25-30 م وييتعد مذه المنارة عن الحرم حوالي 7

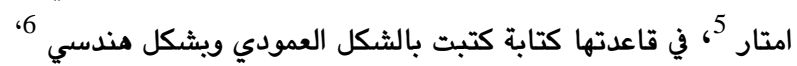

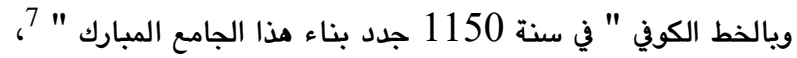
وفي حرم المسجد 8 اعمدة عريضة تحت سقفها المرتفع عن الارض حوالي 10 امتار، اما المحراب فيخرج من الجدار الجنوبي للحرم حوالي 70 سم، في الجدار الايسر للجامع يوجد ثلاثة شبابيك، اما في الجدار 
البدخشاني)، وقبر الشيخ (احمد الحمداني)، وقبر الشيخ (عبد (الشب الخلاق)، وقبر الشيخ (حسن الخيزاني) والتي لا يعرف تاريخ وفاتهم بالضبط، بني الجامع كاقرانها من الحجر الاحمر، للجامع بوابة خارجية،

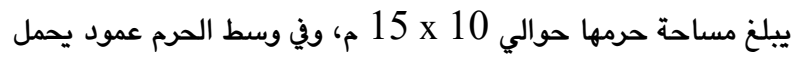
سقف الجامع المقبب من الداخل، وفي الحائط الشمالي للحرم هناك لوحة مزروعة فيها من حجر الحلان الابيض ويطول حوالي 75 سم وعرض من

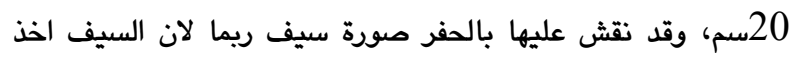
مدلولات دينية في التقاليد الاسلامية، وفي الزوايا الاريعة للقطعة الحلانية نقوش تضفي جمالية عليها، والى غرب القبور الاربعة هناك لوحة حجرية من الحلان الابيض ايضا مليئة بكتابة لم نستطع في الحقيقة فك حرفها وفهم محتواها 19، لا يعرف بانيها اما بخصوص تاريخ بنائها يرجح انها بنيت في سنة 1552 ونمهواهن 7.2 7.2 من الجوامع التاريخية وتقع في حي تاش (طاش) بمركز مدينة بدليس،

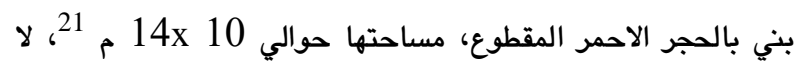
يعرف بالضبط بانيها وتاريخ بنائها، ولكن يذكر شرفخان المؤرخ ان امير بدليس شمس الدين بناها مع زاوية وتسمى المؤسسة بـ (الشمسية) 22، وقد يكون الشمس الدين المقصود هو (شمس الدين الولي) او ريما يقصد شرفخان والده، وقد قام بترميمها شمس الدين ابن شرفخان الخامس سنة 1589م 23

شكلها مستطيل باتجاهي الشمال والجنوب، اما محرابها فيخرج من الحائط بمقدار قرابة 60 سم، والى جانبي المحراب هناك شباكين صغيرتين، بابها الخارجي مزخرف بزخارف جميلة، طوله 25، 3 م

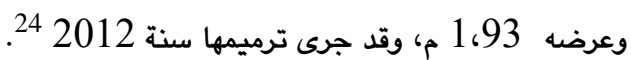

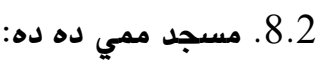

مسجد صغير الحجم، يقع في مركز مدينة بدليس على حافة من حافات نهر بدليس مباشرة، بني بالحجر الاحمر جنوب ، ويخصوص تاريخها يظهر من كتابة على بوابة المسجد انها بنيت سنة 1572 م 25. 9.2 جامع الشيخ الغريب: يقع في مركز بدليس، مبنية من الحجر الاحمر، ويقع تحتها قبر الشيخ الغريب مكتوية في اعلى يسار بوابة القبر التاريخ 1042 هـ، والذي مني يصادف سنة 1632 م، وقد جرى ترميم المسجد سنة 1879 م 26. 10.2 . جامع عين الباروت ( عين البارد): جامع صغير يقع في مركز مدينة بدليس ايضا شرق قلعتها، في حي

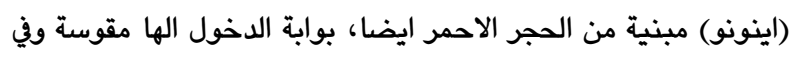
اعلاها 3 قطع حجرية ذي حواجب، وعلى القطعة الوسطى تم رسم صورة وردة محفورة بارزة للخارج، والجامع بني على عين ماء بارد جدا يخرج من تحتها ليكون مكانا للوضوء، وفي الجامع قبر يعود لرجل دين

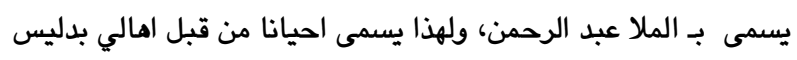
بجامع الملا عبد الرحمن، وهناك شبابيك في الحيطان الشرقية والغربية
و3 شبابيك صغيرة هي اقرب لان يكون فتحات تهوية او ممرات لخروج دخان المدافئ الخشبية ومدافئ الفحم الحجري في الشتاء، وفي اعلى لى لهرب الحائط هذا اسفل السقف مباشرة هناك زخرفة تعطي ايضا جمالية للحائط، تقدر مساحتها قرابة 18 x 14 م، وهي بذلك تتسع لقرابة 250 مصليا، ولا تحتوي المسجد على قبب على سقفها، ويداخل الحرم ستة اعمدة مريوطة مع بعضها باقواس مقببة تحمل سقف المسجد 15 5.2. جامع ومدرسة الشرفية: من امم المعالم الاثرية في بدليس، جامع كبير يقع في مركز المدينة، مكون من اقسام، حرمها كبير مقارنة بجوامع اخرى موجودة في بدليس،

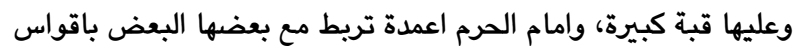
هندسية، سمي بهذا الاسم تيمنا ببانيها الامير شرفخان الرابع سنة 1528، وهذا ما يستدل من لوحة على احدى البوابات طولها قرابة

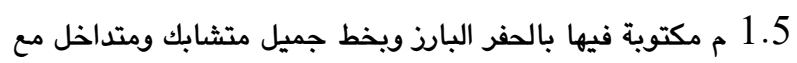

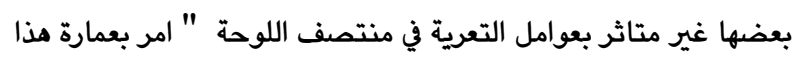
المسجد شرف بك 935 "، وعلى اللوحة هذه نقوش وزخارف رائعة جدا، بني من الحجر الاحمر16، ويذكر شرفخان البدليسي ان جده شرفخان الرابع بنى جامعا ومدرسة وزاوية وان كلها سميت بـ " الشرفية

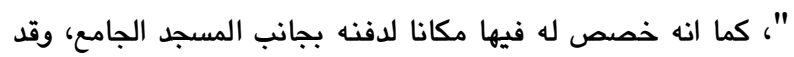
دفن به، وان زوجته ( شاهـ بيكي خاتون بنت علي بك الصاصوني ) قبة عالية عليه واتمت بناءها ثم عين حفاظا للقران عليه لتلاوة القران عليه صباح مساء 17. اغلب جدران الجامع والمدرسة والزاوية منقوشة باشكال هندسية جذابة، لها باحة وحوش كبير، داخل مذا الحوش مقبرة تضم قرابة 15

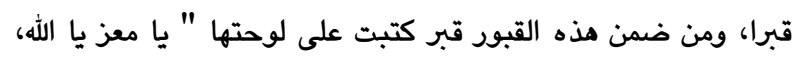

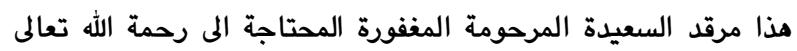
وغفرانه فرخندة خانم بنت شرف بك غرزاني 1092 " وكذلك قبر اخر كتبت على لوحتها انها قبر " فردوس خاتون والدة عطا بيك وعليها تاريخ 1124 "، كما وفيها منارة طويلة مرممة طولها حوالي 20- فردوسيت 25 م، وفي حجرة مستطيلة الشكل ذات قبة قاعدتها سداسية الزوايا وذات بوابة حجرية مقوسة قبر شرفخان الرابع، وعلى بوابة هذه الحجرة لوحة مساحتها 100 x 15 سم بيضاء اللون فيها كتابة محفورة للخارج غير واضحة المعالم في اغلبها، لانها كما يبدو تأثرت بعوامل التعرية والزمن، ولكن في الزاوية السفلية اليمنى من اللوحة يظهر جزء

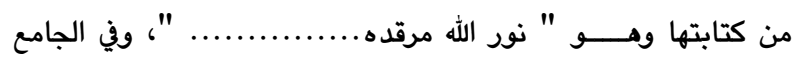
ايضا حجرات اخرى مقببة، كما وفيها صالة واسعة تتوسط حجرات كانت تستخدم لدراسة العلوم الدينية فيها 18. 6.2. جامع دورت ساندك (التوابيت الاربعة): ويقع هذا الجامع ايضا في مركز مدينة بدليس في حي كوك ميدان، وهو ايضا من الجوامع الكبيرة الى حد ما، لها حوش وياحة مشجرة، سمي مدي لهريس بهذا الاسم لوجود 4 قبور في باحتها، ومم كل من قبر الشيخ (عبدالله 
18.2. جامع اسكندر باشاـ خلاط: يقع في خلاط، بني من قبل اسكندر باشا احد وزراء السلطان سليمان

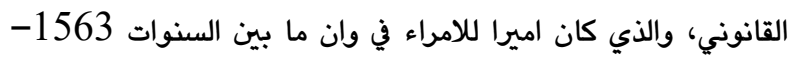

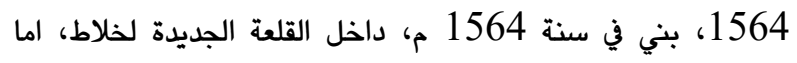

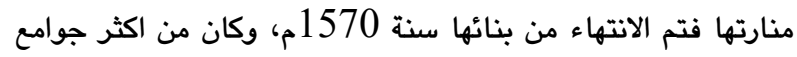

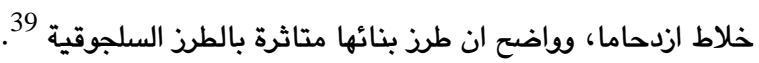

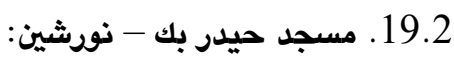

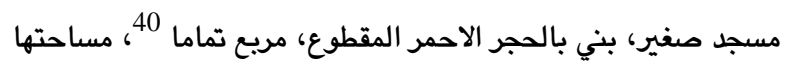
حوالي 9.50 x 9.50 م، اما ارتفاعها فيبلغ حوالي 5 امتار، لها

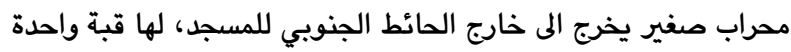
غير مرتفعة، لا يعرف تاريخ بنائها بالضبط غير لكن يخمن انها بنيت

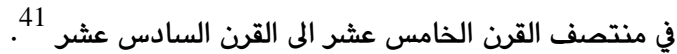
20.2. جامع اولو جامي (الجامع الكبير) (فرهاد بك)- موش: يقع هذا الجامع في ناحية موش التي كانت تابعة لبدليس من الناحية الادارية لفترات طويلة، بني هذا الجامع من احجار غير مقطوعة مختلفة كأنة x الاشكال والاحجام والالوان، يبلغ مساحة حرم الجامع حوالي 20 10 م، يحتوي على 3 شبابيك متوسطة الاحجام واخرى صغيرة في اعلاهم، عليها قبة كبيرة ثمانية الزوايا، كما يحتوي الجامع على منارة

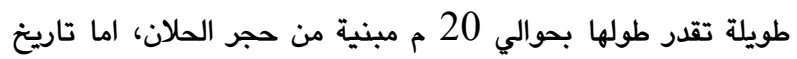

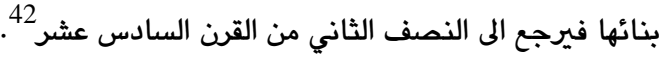
21.2 جامع حجي شرف - موش: يقع الجامع هذا في موش، بني ايضا باحجار مختلة الاشكال والاحجام اضافة الى احجار مقطوعة حمراء كاخواتها في مركز بدليس، لها منارة تقدر طولها بحوالي 20 م، على سطحها مجموعة من القبب الصغيرة،

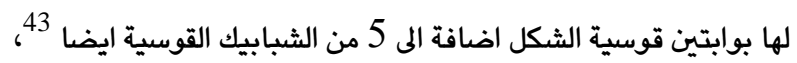

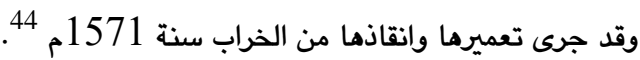

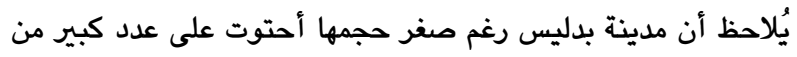

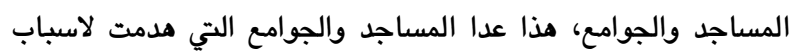
مختلفة، وهذا يعكس تعلق ساكنيها بالديانة الاسلامية وتمسكهم

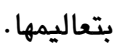

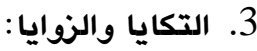

الى جانب المساجد والجوامع التاريخية في بدليس انتشرت فيها عدد من

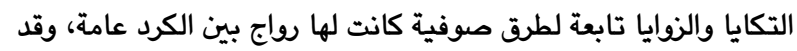

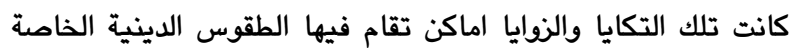
بالصوفية الى جانب قيام الدراويش والصوفيين فيها بتامين الطعام والشراب والمنام دون مقابل لعابري السبيل. وكان شيخ الطريقة يعين بتكليف من القاضي في المنطقة ويمرسوم

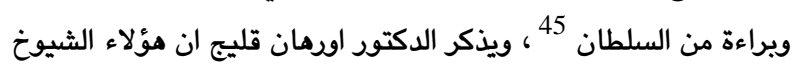

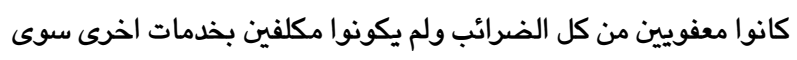

كمصادر للانارة في ساعات النهار، الجامع مكون من طابقين، ولاجل

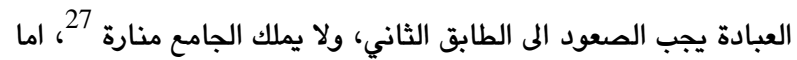
بنائها فيعود الى سنة 1664 128 في في عهد الامير عبدال خان.

11.2 تقع شمال قلعة بدليس، بني بالدجر الاحمر المقطوع، لها باب واسع

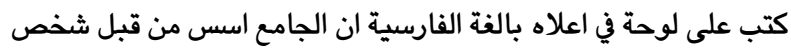

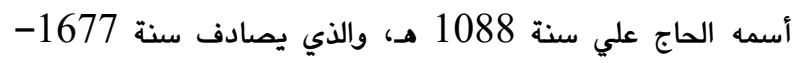
.$^{29} 1678$ 12.2. جامع اشاغي كاله (قلعة اشاغي): يقع في مركز مدينة بدليس، لا يعرف بانيها والفترة التي بنيت فيها

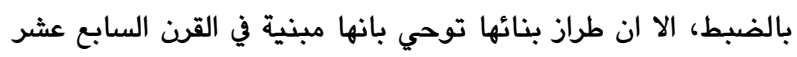

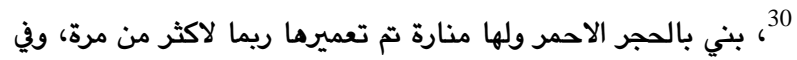
داخل الحرم عمود كبير يحمل السقف المقبب من الداخل 31 بـ

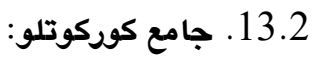
يقع في حي حرسان في مركز مدينة بدليس، بنيت باحجار مقطوعة، لا لا

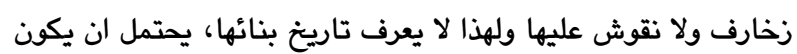

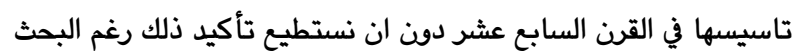
الجاد في الموضوع 32. 14.2 14 جامع الشيخ عبد الملك - خلاط: يقع هذا الجامع في خلاط، بني من قبل شخص اسمه الشيخ عبد المبل الملك سنة 1325 م، وكتب في لوحة حجرية منقوشة في الجبهة الشمالية

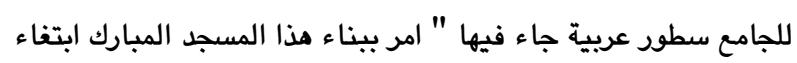

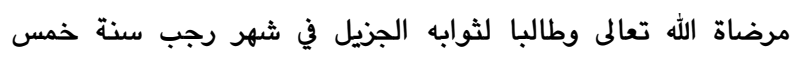
وعشرين وسبع مائة " ويضم هذا المسجد مقبرة ايضا 33 وناليا

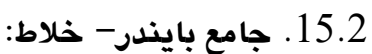

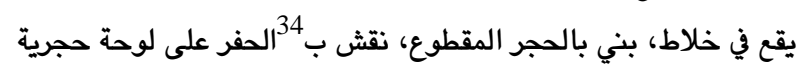

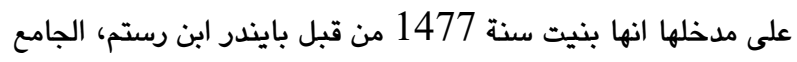
يتكون من جزئين رئيسيين، الاول هي بمثابة ايوان، اما الجزء الثاني

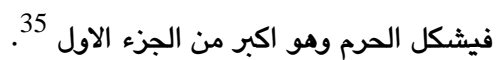

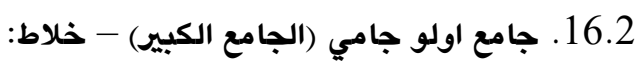
هذا الجامع عبارة عن خرائب واطلال، يخمن انها دمرت من قبل الكير) الصفويين سنة 1522 36، ورد اسمها في دفتر تحرير بدليس لسنة 1540

17.2. مسجد محمود القاضي- خلاط: يقع في خلاط ايضا، مسجد صغير، بني من قبل القاضي محمود داخل ملاطل

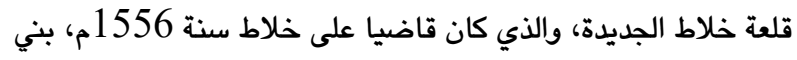
المسجد بالحجر المقطوع سنة 1584م، حرمها مستطيل الشكل،

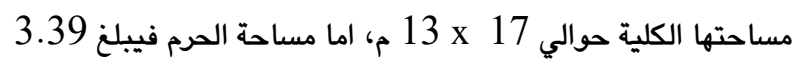
م 3.39 م، لها 3 شبابيك تعتبر مصدر الاضاءة للمسجد في النهار،

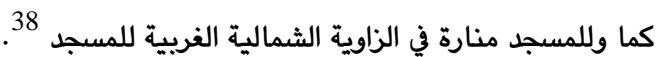


كانت من احدى اهم الزوايا، وكانت تقع في ناحية خلاط وعلى بعد 7-

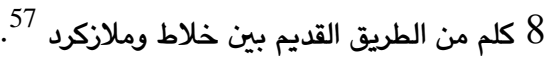
وكانت هناك 6 تكايا اخرى في ناحية كواش

12.3 زاوية الشيخ عبد القادر- خلاط:

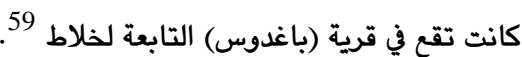

13.3 زاوية قلاقسز- خلاط 14.3

14.3 زاوية شهيدلر(الشهداء) - خلاط.

15.3 زاوية الشيخ يولداش - خلاط.

16.3 زاوية الشيخ محمد سحر هيز - خلاط.

17.3 زاوية الشيخ نجم الدين - خلاط.

18.3 زاوية الشيخ عبد الرحمن - خلاط.

19.3 زاوية الشيخ ابراهيم - خلاط.

20.3 زاوية الحاج حسين الحرراني - خلاط : كانت تقع في الفرالين

مركز مدينة خلاط

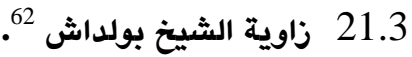

22.3 زاوية الشيخ عمار الخلاطي - خلاط 21.3

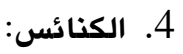

تواجدت في بدليس الكنائس والاديرة ايضا بسبب التواجد الملحوظ للمسيحيين الارمن فيها، ولعل التعايش السلمي بين الكرد المسلمين والارمن المسيحيين كانت سمة ايجابية من سمات وملامح الحياة الاجتماعية في بدليس، لدرجة لا يعثر باحث على ثغرات او احتقانات او

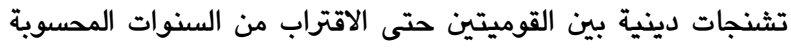
على التاريخ المعاصر في نهايات القرن التاسع عشر ويدايات القرن العشرين، لذا كانت بدليس من المناطق الخالية تماما من الحساسيات الدينية، بل تميزت باحترام القوميتين لتعاليم وتقاليد ديانات بعضهما البعض، ولعل من ابرز هذه الاديرة والكنائس التي تواجدت في بدليس

\subsection{4}

كان دير قدودس قد بنيت سنة 181 1ام في جزيرة اختمار الواقعة في الزاوية الجنوبية الغربية لبحيرة وان، اقيمت على ارض مسطحة، وتعني

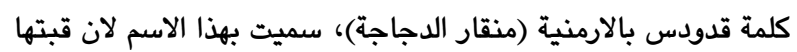

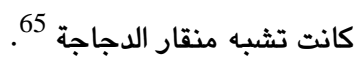

$$
2.4
$$

وتعني صوب خاج باللغة الارمنية (العلاقة المقدسة)، بنيت من قبل شخصين من حواريي عيسى عليه السلام 66 . 3.4
ايواء وخدمة عابري السبيل، لكن عدد الزوايا (التكايا) في بدليس والمدن الاخرى في غرب وجنوب بحيرة وان كانت اقل بكثير من عدد الزوايا

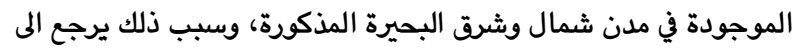
ان التجار والحملات العسكرية كانت تختار وترجح الطرق السالكة شمال البحيرة بسبب قسوة وشدة البرد في مدن الساحل الجنوبي للبحيرة في

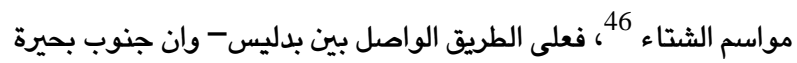
وان كانت هناك فقط 7 نوايا، اما على الطريق الشمالي الواصل بين

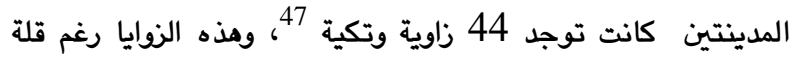

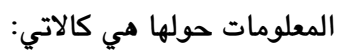

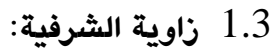

كانت من امم التكايا واكبرها في بدليس، بنيت سنة 1540 مارية 1540 مع جامع

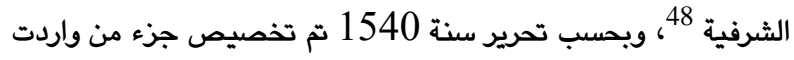
الجامع والتكية للامام والمؤذن والخادمين والكتبة، وجزء منها يتم

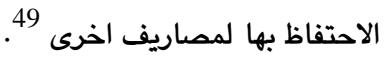
2.3

كانت من ضمن التكايا في بدليس، وكانت لها واردات 3 دكاكين كوقف

3.3

ورد ذكرها في دفتر تحرير سنة 1556 على انها من تكايا بدليس، اما

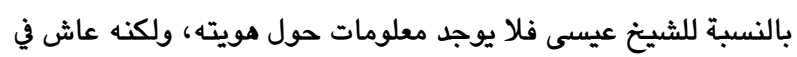

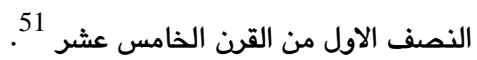
4.3 تقع في بدليس، كانت واردات اوقافها 9690 اقجة عثمانية سنة 1571 الحئيس 5.3 تقع في مركز مدينة بدليس، في سنة 1571 كان شيخ التكية ومدرسها شخص باسم الشيخ عبدالله 53.

6.3 كانت تقع في قرية اروس في ناحية كولتيك التابع لبدليس، في سنة 1571 كان الشيخ بهلول شيخا للتكية الذي خلف اباه الشيخ مجنون

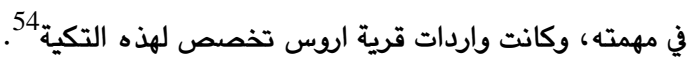
7.3 كانت تقع في ناحية كواش التابعة لبدليس 55.3 8.3 كانت تقع في ناحية خلاط التابعة لبدليس 56.3 9.3 10.3 زاوية عبد الباقي افندي. 11.3 
موقع هذه الكنيسة تقع الى الشرق من مدينة بدليس بمسافة 7 كيلومترات، تقع خارج قرية بور الذي كانت من المراكز الدينية المهمة للمسيحيين الارمن، يخمن ان الدير بنيت في فترة السلاجقة او في الفترة

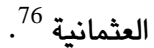

12.4

13.4

14.4

15.4

16.4 دير اندوجانيبن.

17.4

18.4 دير ضوروش.

19.4 دير عارفة (ارفة).

20.4

21.4

22.4

23.4

جدير بالأشارة اليه ان الباحث لم يتمكن من العثور على معلومات أكثر حول الكنائس والأديرة السالفة الذكر، اذ يكاد ينعدم ذكرها في المصادر

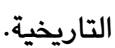

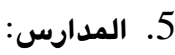

كانت بدليس مركزا من مراكز الاشعاع العلمي باستمرار قبل واثناء العهد العثماني، ولم تخلو في الحقيقة من المؤسسات العلمية التي كانت متطورة جدا قياسا بمناطق اخرى في كردستان والمناطق المجاورة لها، كما وانتجت بدليس علماء وادباء وشعراء عظام من الذين اصبحوا من

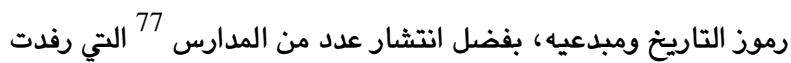

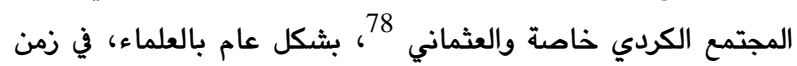

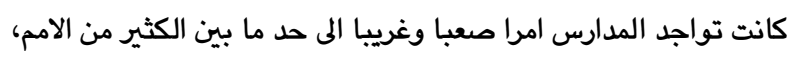

$$
\text { ومن ابرز هذه المدارس كانت : }
$$

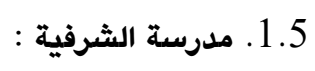
تم بناءها ضمن مجموعة أبنية الشرفية من قبل الامير شرفخان الرابع

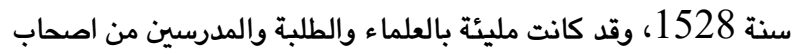
الفضل والادب حسب ما يشير الى ذلك الامير شرفخان الخامس، من

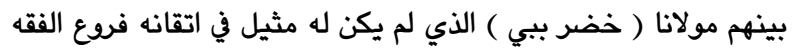
الشافعي وكذلك في التفسير والحديث

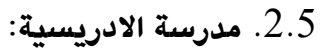
تقع في مركز مدينة بدليس، بنيت من قبل الملا ادريس البدليسي سنة 1515 بجانب قبر الشيخ طاهر الكردي الذي بناه الشيخ حسام الدين
بنيت هذه الكنيسة في جزيرة اختمار لتكون قاعدة دينية يتبعها كافة

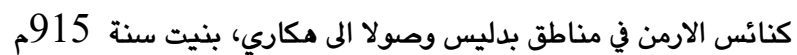

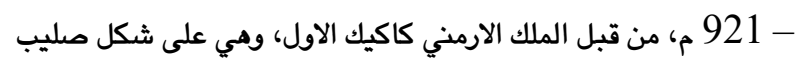

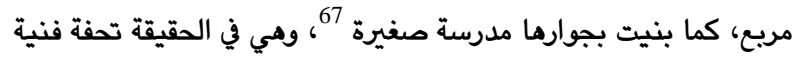
معمارية رائعة جدا، فائقة الجمال، نادرة المثيل، بني بالاحجار المقطوعة، لها قبة كبيرة تعلوها الصليب، هذه القبة يتضمن 8 شبابيك

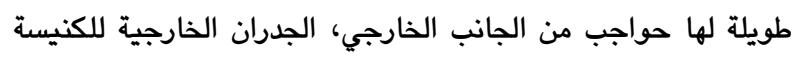

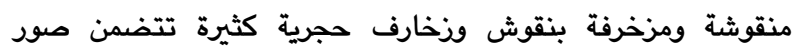
ومجسمات الحواريين والقديسين الاوائل، ومجسمات بعض الاشجار

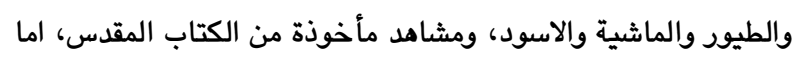

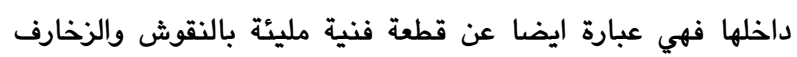

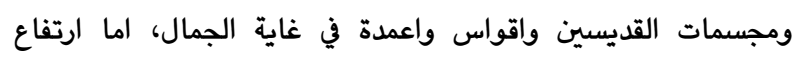
الكنيسة من الارض للمليب المرفوع على قبتها فيبلغ قرابة 20 م

4.4 بنيت هذه الكنيسة سنة 950 م وسط سهل رحوا(رهوا) شرق مدينة بدليس، كانت تتبع كنيسة اختمار ، وكانت لها تقدير كبير واحترام

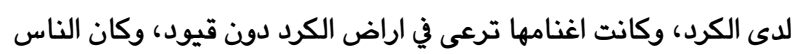

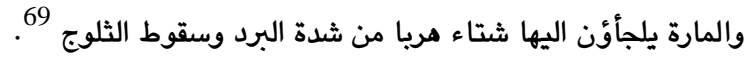
5.4 تقع على جزيرة اختمار ايضا، بنيت سنة 1185 م، كان يمنع فيها اكل المأكولات والتقرب من النساء، كانت خاصة بالعبادة فقط، والى الى

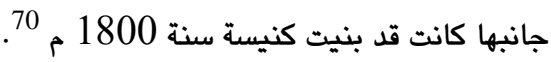
6.4 يقع هذه الكنيسة بين بدليس وتتوان على بعد 4 كيلومترات من التيا:

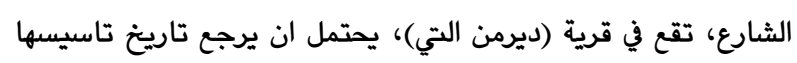

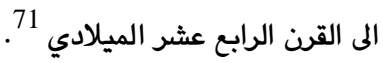
7.4 كانت في قريتي ( زيكاك ومادفانيس) الارمنيتين في الرئ ناحية خلاط كنيستين سنة 7.4. 8.4

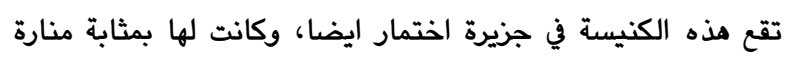
مرتفعة تشرف على الجزيرة كلها وعليها ناقوس كبير جدا 9.4

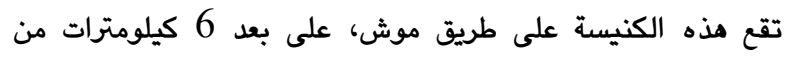

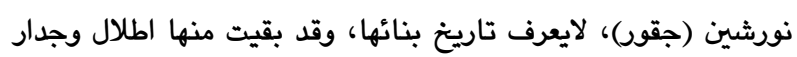
على هيئة دائرة 74. 10.4 بنيت الكنيسة هذه في قرية (اسكي كرمته) على بعد 38 كم جنوب بدليس 11.4 
كردستان بعلو الهمة وسمو المكانة ويمهارة كاملة في علوم التفسير والمنطق والكلام 90.

4.5 مدرسة الخطيبية (الخاتونية)

تقع المدرسة الخطيبية في مركز مدينة بدليس في حي الزيدان في جهتها الجنوبية بجانب تكية ومقبرة الشيخ الغريب مباشرة وعلى بعد حوالي 30-40 م من جامع عالمدار المار ذكرما سابقا، بني في مكان مرتفع

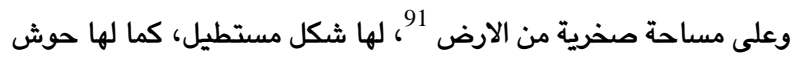
مساحتها 18،9 م * 20،51، وكان القسم الجنوبي من المدرسة من انشط اقسامها بطول 9.18 م وارتفاع 9.73 م، وهي الجهة الغنية بالنقوش اكثر من الاقسام الاخرى، اما القسم الغربي من المدرسة

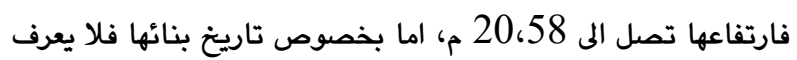
بالصبط، ولكن ولان طراز بنائها تشبه الى حد كبير طراز بناء مقبرة ممي ده ده التي تقابلها يحتمل ان يرجع تاريخ بنائها الى منتصف ولف ولى القرن السادس عشر 92. يقع بوابتها في الجهة الشمالية من البناية وامام البوابة صالة وصالتين في الجهة الشرقية، وفي الزوايا الغربية والجنوب الغربي هناك غرف، بني بالحجر الاحمر المقطوع اضافة الم استخدام واضح لحجر البازلت ايضا، ويبلغ عرض جدران المدرسة كمعدل وسطي قرابة 30، 1 م، اما في الداخل يحتوي بناية المدرسة على اقواس داخلية، لكن خال تماما من النقوش، وعدد من الشبابيك، وفي الزاوية الجنوبية الغربية للبناية يقع احدى الشبابيك التي تزود المدرسة بالانارة وقد نوقشت اعلاها بنقوش وزخارف رائعة تضفي على البناية نكهة دينية علمية مميزة، وكانت تسمى بدار الحديث في بعض الاحيان 93. 5.5 تقع المدرسة في مركز مدينة بدليس، بنيت بالحجر الاحمر المقطوع، وتعرضت اقسام كبيرة منها للخراب، سميت بالشكرية نسبة الى اسم شكري البدليسي 949، يذكر الامير شرفخان الخامس ان المدرسة انشأت بأمر منه 95، يخمن انها بنيت بامر من الامير عبدال خان، ولم تكن لأن تقتصر على العلوم الدينية فقط، بل درست فيها العلوم الاخرى ايضا

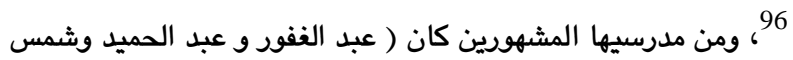

$$
\text { الدين ) }
$$

مدرسة الحاج بكية : ومن مدرسيها المشهورين الشيخ ( محمد الزرقي) الصوفي الذي يشير اليه الامير شرفخان الخامس على انه لم يكن له نظير في اتقانه الفقه، وتمسكه باهداب الزهد والتقى والديانة والصدق لتحي

$$
\text { والاستقامة } 98 .
$$

الاجيال، اذ يشتهر اهالي بدليس حتى في الوقت الحاضر باندماجهم

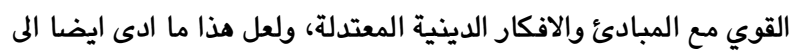
انتشار الافكار والطرق الصوفية والتكايا فيها والتي بالامكان فرذ اهدافها في منحيين اثنين، اولهما العبادة والتعبد والتقرب الى الله عز وجل، ونبذ الدنيا والتزهد والتقشف من اجل تنزيه وتنظيف الروح من
والد ادريس البدليسي ، ورغم ان شرفخان البدليسي يشير الى انه هو

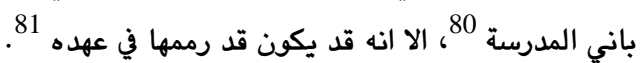
ومن بين مدرسيها المشهورين الشيخ عبد الله الملقب حسب ما يذكره الامير شرفخان الخامس (رشك)(الشيخ الاسود) الذي كان قد مدرئ حصل على البراءة من استانبول، وكان من ابرع العلماء 82.

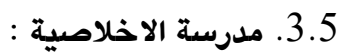
تقع المدرسة هذه في حي كوك ميدان في مركز مدينة بدليس، ضمن مجموعة كبيرة من الابنية، وقد كتبت في اعلى باب المدرسة ويخط مزخرف متشابك جميل محفور للخارج على لوحة حجرية بيضاء طولها

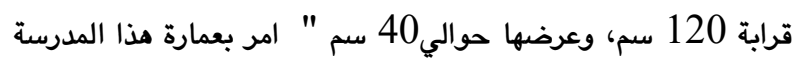
الشرفية المشرفة الشريفة 83....................... قلاخلاصية الخالصة لوجه الامير شرفخان بن المرحوم الامير شمس الدين. الله خان في سبع وتسعماية وتسعين " 85، ويصادف التاريخ المذكور سنة 1589- 1590م، وقد يكون القصد من كلمة (العمارة) هو (الترميم) رغم ان شرفخان يشير بوضوح الى انها انشأت بامر منه ${ }^{86}$ ، لان البناية هون (لتمنية

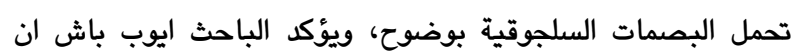

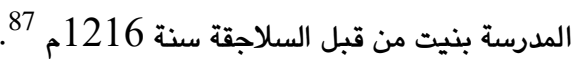
ارضية المدرسة مرتفعة عن الارض حوالي 30 سم، وفي وسطها (البناية) من الداخل قبة، ويتكون المدرسة من اربعة صالات رئيسية، كل صالة يتكون من غرف مختلفة الاحجام، اما باب الخول الى المدرسة فيقع في منتصف الجهة الجنوبية من البناية، وهي في الحقيقة بوابة فخمة جدا ويبرز الى خارج الحائط حوالي 40 سم، وفي المدرسة نقوش عدة محفورة للخارج على احجار والواح مرمرية 88. بنيت المدرسة بالحجر الحمراء المقطوع، وهي مربعة الشكل، مساحتها حوالي 15 م * 15 م، ارتفاعها حوالي 7 امتار، اما نواياها الاربعة من الخارج فيتكون من ابراج تقوية بما يشبه اعمدة دائرية الشكل وعلى كل منها قبة صغيرة، اما مصدر انارتها فهناك 4 شبابيك في الواجهة الرئيسية للبناية بين كل شباكين تم بناء برج صغير مستطيلة القواعد وذي قبب صغيرة خماسية الزوايا، والغاية منها مو اضفاء جمالية على واجهة البناية، و9 ثبابيك اخر موزعة على الحيطان الاخرى الثلاث للمدرسة بمعدل 3 شباك في كل جهة، و 8 شبابيك موزعة بالتساوي في القبة 89. ومن بين اشهر مدريسها الشيخ شمس الدين (محمد الشرانشي) الذي كان معروفا حسب ما يذكره الامير شرفخان الخامس من بين علماء

\section{6. الخاتمة :}

يظهر من خلال تواجد العديد من المساجد التاريخية القديمة في امارة بدليس ان الامارة وامرائها والمجتمع فيها كانوا ذا اهتمام بالديانة الاسلامية وانهم كانوا ميالين للتدين، ولعل ذلك اصبح موروثا تناقلته 
editorler : hasan celal guzel,prof.Dr.kemal cicek,prof.Dr.salim koca,yeni Turkiye yayinlari,(Ankara:2002), cilt 7, S 1088.

8.

9. Yrd. Doç. Dr. Rabia Özakın ,XIII. Yüzyıl Anadolu Selçuklu Cami Mimarisinde Gelişim ve Beylikler Dönemine Etkileri, TURKLER, editorler : hasan celal guzel,prof.Dr.kemal cicek,prof.Dr.salim koca,yeni Turkiye yayinlari,(Ankara:2002), cilt 7, S 1290 ; Turkiye diyanet vakfi islam ansiklopedisi, A.G.E.S 228.

10. Mehmet törehan serdar, rüyalar şehrı bıtlıs, bıtlıs valılı̆ı,hamle yayınları,(Istanbul : 2000),S 160.

11. Turkiye diyanet vakfi islam ansiklopedisi, A,G,E, S 228.

$$
\begin{aligned}
& \text { 12. زيارة ميدانية للباحث في 2015/4/21. } \\
& \text { 13. زيارة ميدانية للباحث في 2014/11/9. نظرا ميدان للاهمية المسجد ودورها العلمي } \\
& \text { في القرنين السادس عشر والسابع عشر تمت الاشارة اليه رغم كونها قد بنيت في اواخر } \\
& \text { النصف الاول من القرن الخامس عشر. }
\end{aligned}
$$

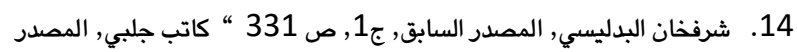

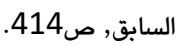

$$
\begin{aligned}
& \text { 15. زيارة ميدانية للباحث بتاريخ 2014/11/12. نارة 2014/11/9. }
\end{aligned}
$$

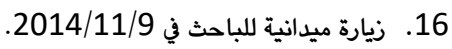

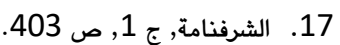

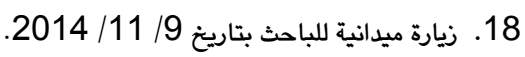

$$
\begin{aligned}
& \text { 19. زيارة ميدانية للباحث في 2014/11/11. }
\end{aligned}
$$

20. celal saydam, bitlis ve beyaz petrol,(Istanbul : 2013),S 114 ; Turkiye diyanet vakfi islam ansiklopedisi, S 228.

$$
\begin{aligned}
& \text { 21. يارة ميدانية للباحث بتاريخ 10/ } 11 \text { / } 2014 .
\end{aligned}
$$

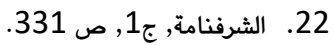

23. şehabettın öztürk,bıtlıs merkez şemsıye mescıdı, VII.ULUSLARARASI VAN GÖLÜ HAVZASI SEMPOZUMU, S 165.

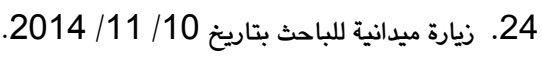

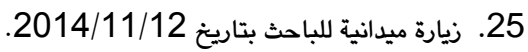

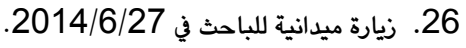

$$
\begin{aligned}
& \text { 27. زيارة ميدانية للباحث في 2015/4/20. }
\end{aligned}
$$

28. Turkiye diyanet vakfi islam ansiklopedisi,S 228. 29. زيارة ميدانية للباحث في 2015/4/20.

30. celal saydam,A.G.E.S 115.

$$
\text { 31. زيارة ميدانية للباحث في 2015/4/21. }
$$

33. Mithat ESER, SELÇUKLULAR DÖNEMINDE MUŞ VE ÇEVRESI, Turkish Studies - International Periodical For The Languages, Literature and History of Turkish or Turkic Volume 9/1 Winter 2014, p. 185-207, ANKARATURKEY, S 201.

35. www.bitlis cami ve mescitler.com.

36. DOÇ.Dr.orhan kılıç,XVI.Yüzyılda ahlat, S 30.

37. Tapu tahrir defter, no : 413, S 09.

Rehmı tekın, ahlat tarihi, S 135.: وللمزيد حول هذا الجامع راجع

38. Berikan tarih ansiklopedisi,296 ; DOÇ.Dr.orhan kılıç,XVI.Yüzyılda ahlat, S 31.
الخطايا، وثانيهما لاجل تقديم العون والمساعدة لعابري السبيل من الغرباء، وهي في الحقيقة كانت اسمى صور التكافل والتكاتف الاجتماعي التي كان البدليسيون يهتمون بها. ومن جانب اخر كانت التواجد الكثيف للكنائس والاديرة المسيحية في امارة بدليس تعني تنوع النسيج الاجتماعي والديني في بدليس والحرية الدينية المطلقة التي كان المسيحيون يتمتعون بها بين الكرد، واحترام الطرفين لمعتقدات بعضهم البعض.

اما مدارس بدليس المتقدمة فكانت في الواقع مكمن فخر للبدليسيين انذاك، اذ تخرجت من تلك المدارس التي كانت ذا شهرة كبيرة في المنطقة انذاك المئات من العلماء والفقهاء من حملة العلوم والفكر، ادى الى تقدم الامارة في مختلف النواحي الحياتية، وهذا ما يلاحظ بسهولة لدى البدليسيين، اذ كانوا مختلفين في مجال العلوم والفنون مع كل الامارات الكردية المتواجدة انذاك بفضل مدارسها الكثيرة. ويالنظر الى الاثار المتبقية في بدليس سواء المساجد او الكنائس او المدارس او غيرها من الجسور والحمامات والخانات يظهر جليا التقدم العمراني والهندسي البديع لدى البدليسيين وتفننهم الرائع في فنون العمارة، ويمتانة عديمة النظير، لدرجة ان ابرز ملامح العمارة وسماتها لا زالت شاخصة للعيان، ويمنتهى الجمال رغم مرود المئات من السنين

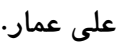

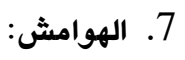

1. جدير بالاشارة اليه ان المسجد بني في اواخر النصف الاول من القرن الثاني عشر,

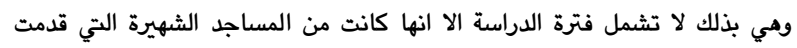

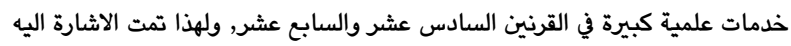
اضطرارا.

2. Turkiye diyanet vakfi islam ansiklopedisi, türkıye dıyanet vakfı yayınları, Bıtlıs doğu anadolu bölgesınde şehır ve bu şehrın merkez olduğu Il,(Istanbul : 1992), cilt 6, S 225-228; II van golu havzası sempozumu, s 200.

3. Mehmet sidik arvasi, 298 numareli ;eriye sicili defterine göre bıtlısın ekonomık sosyal ve dını durumu, Yüksek Lisans Tezi,marmara ünverstesı,sosyal bılmler enstıtüsü,ılahıyat anabılım dalı,ıslam tarıhı bılım dalı,(Istanbul : 2007),S 15.

4. yrd.doç Dr.ılhan erdem,doğu anadolu türk devletlerı, TURKLER, editorler : hasan celal guzel,prof.Dr.kemal cicek,prof.Dr.salim koca,yeni Turkiye yayinlari,(Ankara:2002),cilt 6 ,S 697 Turkiye diyanet vakfi islam ansiklopedisi, A.G.E. S 228.

5. 5يارة ميدانية للباحث بتاريخ 2014/11/9.

6. yrd.doç.Dr. abduülhamıt tüfekçıoğlu, Türk mımarısınde yazı, TURKLER, editorler : hasan celal guzel,prof.Dr.kemal cicek,prof.Dr.salim koca,yeni Turkiye yayinlari,(Ankara:2002), cilt 6,S 162.

7. Prof. Dr. Oktay Aslanapa ,Anadolu Selçukluları ve Beylikler Devri Kültür Sanatı, TURKLER, 
الموجودة فانها بنيت سنة 1784 م, ولكن يبدو من كتابة منقوشة اخرى انها رممت في سنة 1828 م وجامع القادرية والمبنية سنة 1810 وجامع كالو المبنية في بدايات

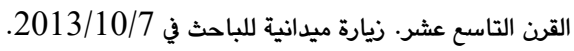

39. DOÇ.Dr.orhan kılıç,XVI.Yüzyılda ahlat, S 30 ; Mithat ESER, A.G.E, S 201-202 ; Berikan tarih ansiklopedisi, berıkan yayınları,(Ankara : 2002) ,S 296.

40. يارة ميدانية للباحث في 6/26 / 2014.

41. Bülent Nuri KILAVUZ, GÜROYMAK HAYDAR BEY CAMii ,Uluslararası Sosyal Araştırmalar Dergisi Social Cilt: 6 Sayı: 25, S 293.

$$
\text { 42. . زيارة ميدانية للباحث في 10/8/ }
$$

44. Orhan kiliç, 1571 tarihli mufasal evkaf tahrir defterine göre ercış, bargırı (muradiye) ve muş vakıfları,S 255 .

45. Ahmet yeşar ocak,zavıye,ıslam ansıklopedısı,(Istanbul : 1986 ), c. XIII, S 471-472. 1571 tarihli mufasal evkaf tahrir: 46 ينظر دراسته defterine göre ercış, bargırı (muradiye) ve muş vakıfları, s 253.

47. Ervak yayinlari, 1.Uluslararasi türk dünyası eren ve evlıyaları kongre bıldırılerı,S 318.

48. A.E.S 311.

49. tapu tahrir defter, no : 413.

50. Ervak yayinlari,A.G.E.S 312.

51. Rahmi tekin, BITLIS VAKFIYE KAYIT DEFTERI'NE GÖRE BITLIS VAKIFLARI, S 86.

52. Ervak yayinlari, $A, G, E, S 312$

53. A.E.S.

54. Ervak yayinlari ,A.E.S 312.

55. A.E.S 315.

56. A.E.S 317.

57. Rahmi tekin, Ahlat tarihi, S 141-142.

58. لمزيد حول هذا الموضوع راجع :

Ömer lütfı berkan, osmanlı ımparatorluğunda bır ıskan ve kolonızasyon olarak vakıflar ve temlıkler ıstıla devırlerının kolonızatör türk dervışlerı ve zavıyeler, vakıflar dergısı, S 279-365.

59. Rahmi tekin, ahlat tarihi, S 139.

60. A.E.S 143.

61. Rahmi tekin, ahlat tarihi, S 143

62. A.E.S 142.

63. Tapu tahrir defter,Sira nu : 413, S 209 DOÇ.Dr.orhan kılıç,XVI.Yüzyılda ahlat S 31-32.

64. سيتم ادراج كنائس واديرة تم بنائها في فترات قبل القرنين السادس عشر واد

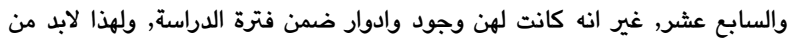

الاثاة اليها.

65. ميرزا موسى خان طباطبائي انصاري, زبدة الوقائع, نسخة المكتبة المركزية

في جامعة طهران رقم 2642, ورقة 327, (نسخة مصورة منها بحوزة الباحث).

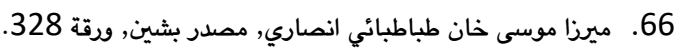

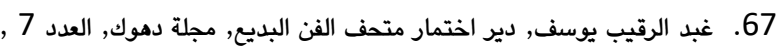

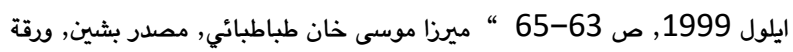

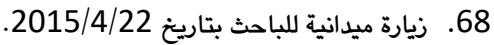
69. ميرزا موسى خان طباطبائي انصاري, مصدر بشين, ورقة 327.
ومن الجوامع الشهيرة في بدليس ايضا كانت جامع كوك ميدان : يقع هذا الجامع في

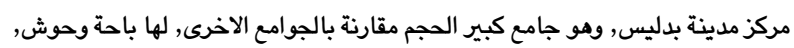

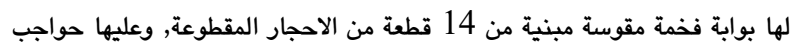

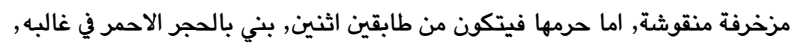

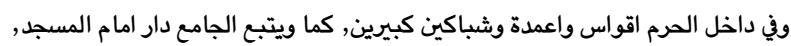
لها منارة مبنية بهندسة وزخارف ونقوش تعكس براعة بانيها, وطويلة يتراوح طولها

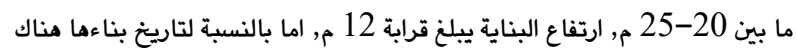

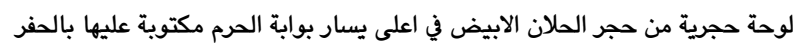

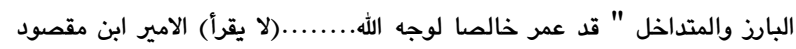

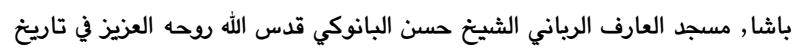
سنة الف ومأتين وستة عشر من الهجرة النبوية للمصطفى ل.....(لا يقرأ) " وعليه

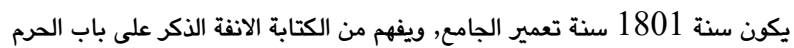

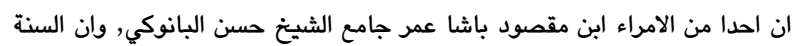

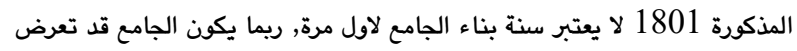

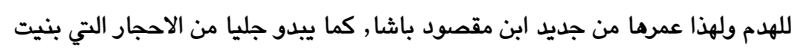

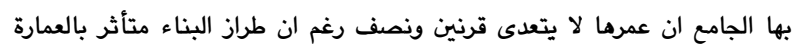

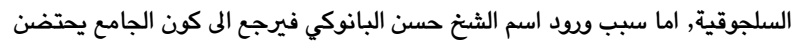

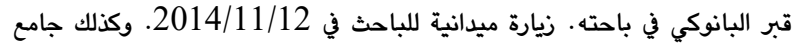

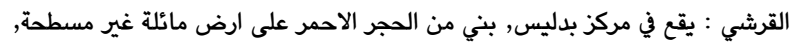

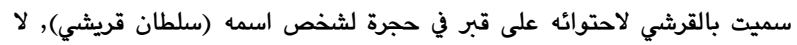

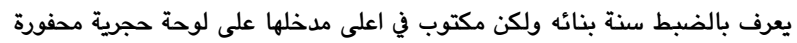

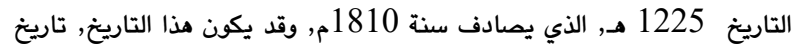

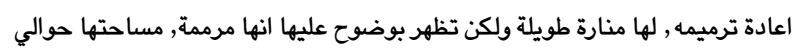
6 X 12 م, اما ارتفاعها فيبلغ حوالي 6 امتار في جنوبها وحوالي 3 امتار في شمالها, ليس لها باحة او حوش, محرابها بارز الى خارج حائط المسجد الجنوبي بمقدار 50

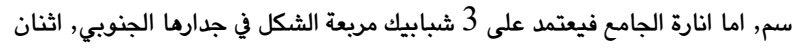

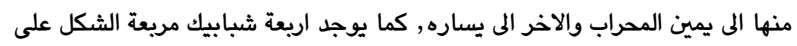

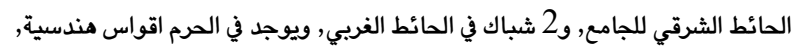

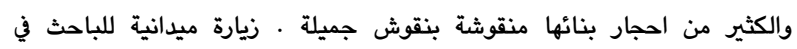

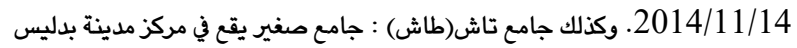

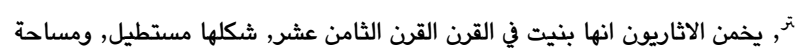

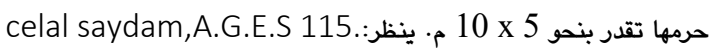

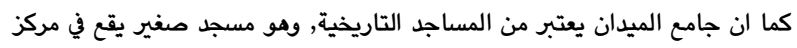

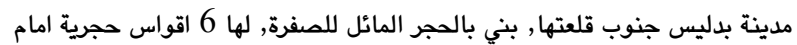

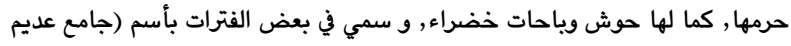

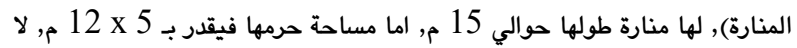
يعرف بالضبط زمن بنائه ولكن يرجح انها بنيت في القرن الثامن عشر, وقد تم ترميمها ماحسا

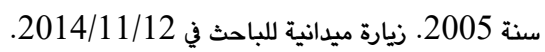
وجامع ابسل اغا والذي يقع في مركز المدينة, بني من الحجر الاحمر المقطوع, ليس ليس

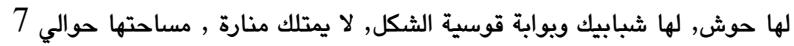
10 x بدليس.زيارة ميدانية للباحث في 2014/11/12. و جامع قربولاق : يقع في مركز

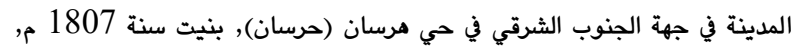

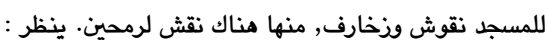

Gülşen baş, bitlıstek1 mımarı yapılarda süsleme, bitlıs valılığ1 kültür yayınları,(bitlis : 2002), S 44-45.

وجامع السلطانية : تقع في مركز المدينة, بني بالحجر الاحمر, مكون من طابقين

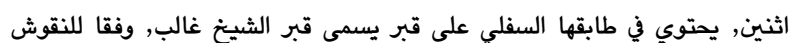


93. زيارة ميدانية للباحث بتاريخ 2015/4/22.

94. سنقف على هذه الشخصية البدليسية لاحقا.

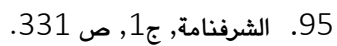

96. ويارة ميدانية للباحث بتاريخ 13 / 11 / 11 / 2014.

97. Mehmet siddik arvas,A,G,E,S 71 .

98. الشرفنامة, ج1, ص332.

ومن المدارس الشهيرة الاخرى في بدليس كانت مدرسة اليوسفية : يقع هذه المدرسة

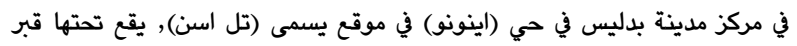

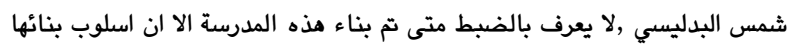

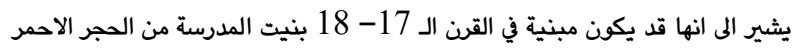

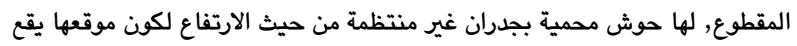

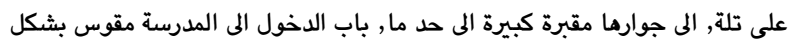

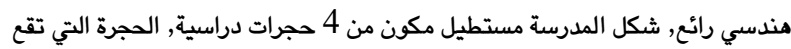
الى اليمين من البناية مربع وعليها قبة بخلاف الحجرات الـ 3 الاخرى المستطيلة الشكل, كما انها تحتوي على 4 اقواس داخلية, والحجرات تاخذ انارتها من شبابيك

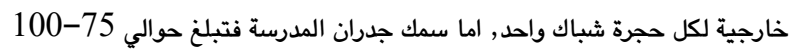

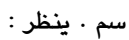

Yrd. Doç. Dr. Zerrin Köşklü ,XVII ve XVIII. Yüzyıl Osmanlı Medrese Mimarisi, TURKLER, editorler : hasan celal guzel,prof.Dr.kemal cicek,prof.Dr.salim koca,yeni Turkiye yayinlari,(Ankara:2002), cilt 12,S 254 ; celal saydam,A.G.E.S 121 ;

زيارة ميدانية للباحث بتاريخ 10 / 11/ 2014. كما كانت مدرسة النوحية من المدارس ذات الاهمية في امارة بدليس, وتقع هذه

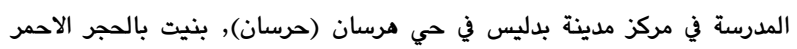

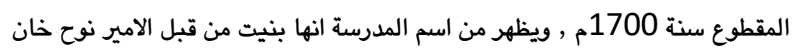

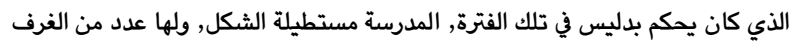

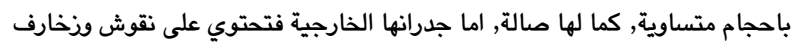

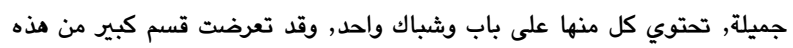
المدرسة للخراب, كما واستخدم لفترات كمقر عسكري من قبل الجيش التركي. ينظر: celal saydam,A.G.E.S 121 ; زيارة ميدانية للباحث بتاريخ 13 / 11 / 2014.

اما مدرسة الاخلاقية التي بنيت سنة 1801 فكانت لها دورها ايضا الى جانب

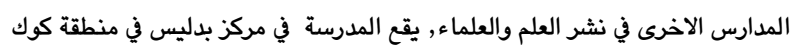

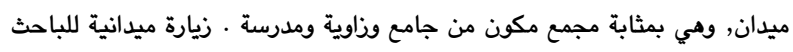

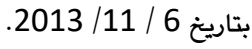
بالاضافة الى هذه الددارس كانت هناك في بدليس مدارس اخرى تعود تاريخ بناء اغلبها الى ما بين القرنين الثامن عشروالتاسع عشر, ومنها مدارس (القادرية, الخليلية, غازي بك). زيارة ميدانية للباحث بتاريخ / 11 / 11 / 2014.

$$
\text { 70. ميرزا موسى خان طباطبائي انصاري, مصدر بشين, ورقة } 325 .
$$

71. Kadir PEKTAŞ Gülşen BAŞ, A.G.E.S 51.

72. DOÇ.Dr.orhan kılıç,XVI.Yüzyılda ahlat,S 33.

$$
\text { 73. } 13
$$

74. Kadir PEKTAŞ Gülşen BAŞ, GÜROYMAK VE TATVAN'DA 2000 YILI ARAŞTIRMALARI, 19. ARAŞTIRMA SONUÇLARI TOPLANTISI, 28 MAYIS-OI HAZIRAN (ANKARA : 2001), I.CILT, S 51.

75. Kadir PEKTAŞ Gülşen BAŞ, A.G.E.S 51.

76. Yalçın karaca, bıtlıs saınt jean manastır(porayvank) ve ıkı neflı jamatunlar üzerıne bır değerlendırme, IV Uluslararası van gölü havzası sempozyumu.

77. للتفصيل عن مدارس بدليس واعدادها وكيفية توزيعها على اقضية ونواحي

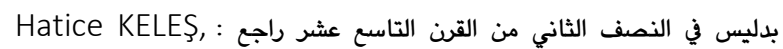
salnamelere göre van ve bıtlıs vilayetlerınde dını-sosyal yapı, yüksek lısans tezı, fırat ünıversıtesı, sosyal bılımler enıstıtüsü, felsefe ve dın bılımlerı anabılım dalı, dınler tarıhı bılım dalı, (ELAZIĞ- 2009), S 24-28.

78.

Anadolu'daki Osmanl Medreseleri: Bir icmal, Türkiye Arafltrmalar Literatür Dergisi, Cilt 2, Say 4, 2004, S 371-

409.

$$
\text { 80. }
$$

81. Dr. rahmi tekin, idrisi bidlisi ve idrissiye bmedresesi mavkufati, A.Ü. Türkıyat araştırmaları enstıtüsü dergısı, sayı 40, (erzurrum : 2009),S240-241.

$$
\begin{aligned}
& \text { 82. الشرفنامة,ج1, ص332. } \\
& \text { 83. لم استطع فك الكلمات وقراءتها. } \\
& \text { 84. كذلك. }
\end{aligned}
$$

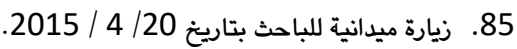

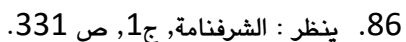

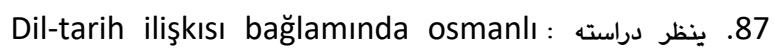
türklerınde arapça tarıh yazııclığı,(XVI.XVII. . YÜZYIL.ÖRNEKLERIYLE, AÜIFDXVI(2005), sayi 1

88. Gülşen baş, $A, G, E, S 36$.

$$
\text { 99. } 89 .
$$

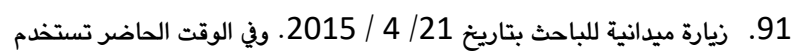

المدرسة الخطيبية كمركز لمكتب مستشارية السياحة التابع لمديرية الثقافة والسياحة

$$
\text { في ولاية بدليس. }
$$

92. Şehabettın öztürk-yuksel bıngöl,Hatıbıye medresesı restorasyonu, VII.ULUSLARARASI VAN GÖLÜ HAVZASI SEMPOZUMU ,S 256-257 ; Gülşen baş,A,G,E,S 43. 


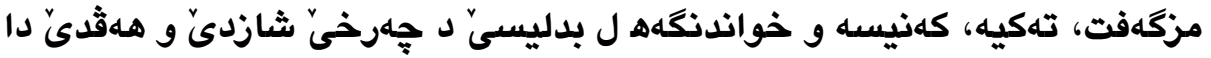

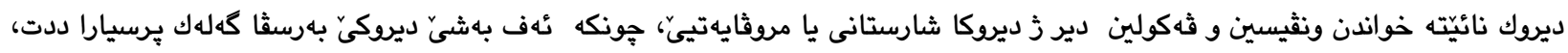

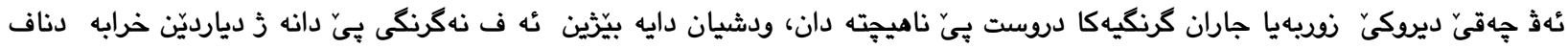

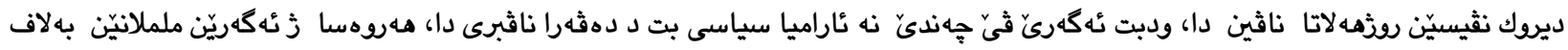

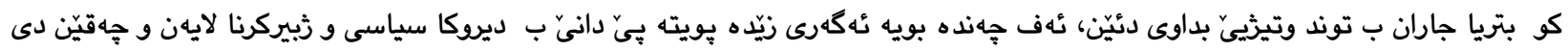

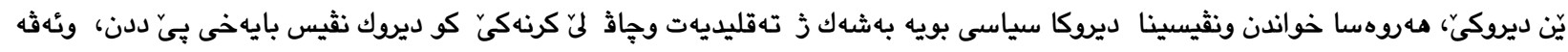

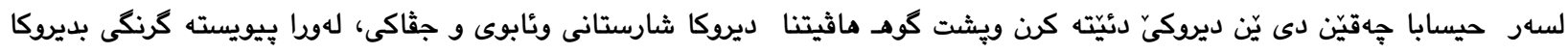
شارستانى بيّه دان مهكهر مه بقيّت ويّنهيهكي دروست يى ديروكى دياريكن، ويتايبهت ديروكا كوردان يا شارستانى كه خودانيّن شين تبلهكا

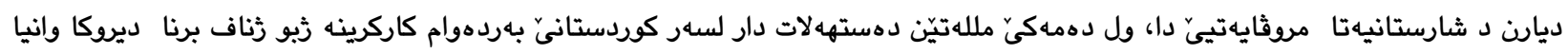

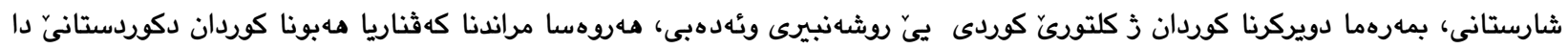
ورولنّ وان دئاثا كرنا شارستانيهتيّ دا.

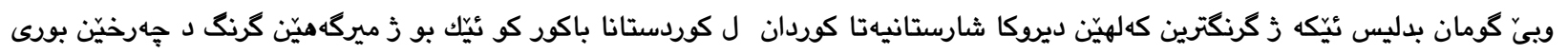

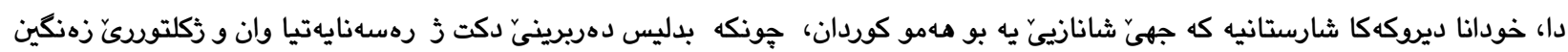

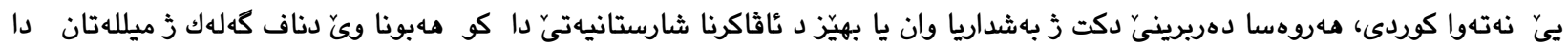

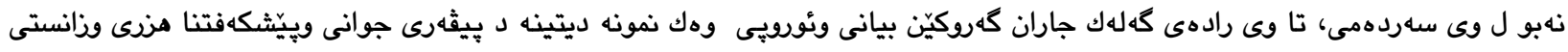

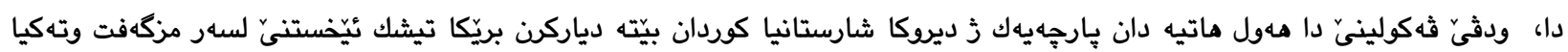

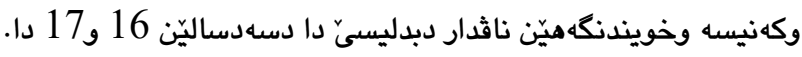

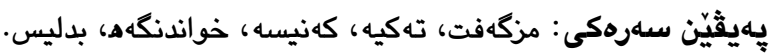

\section{Mosque, Takya, Church and Schools in Badilis in the $16^{\text {th }}$ and $17^{\text {th }}$ Century}

\begin{abstract}
History cannot be study، read and write without the history of urbanization of humanities. In the light of it's a part of history that answer's many questions. This part of history is not taken into account many times correctly. It is noteworthy to say that this kind of neglect is inaccurate among the historian of the Middle East the reason behind of this might be unstable of the region politically. Additionally، the conformational reasons، which ended up by violence many times. This was being a reason of taking into account political history and ignoring other parts of it، likewise r reading and researching of the political history are being a part of traditional' taking and using the same approach of writing history. This is on the other parts of historical account ignoring the urbanization history، economy، and society. Hence، it's necessary to take the urbanization history into account if it wants to show a clear picture، especially the urbanization history of Kurds in which they had great role in the human urbanization، meanwhile the ruling nation who had power on Kurdistan were always working to devastate its urbanization history with the aim of destroying Kurdish culture، intellectuality and literatures in addition to demolish of ancient Kurds in Kurdistan and their roles in constructing of urbanization.

Certainly، Badilis is one of the most significant castle in the urbanization history of Kurdish in southern Kurdistan' which was one of the crucial emirate in the prior century ، it has urbanization history that makes Kurds proud of it. As Badilis depicts its originality of its rich culture of Kurdish nation' likewise، it shows its powerful participation of constructing urbanization that shows its being among many nations at that time. Quite naturally، even many foreign visitors and Europeans brought it as an example of measuring its beauty، development of ideas and sciences.
\end{abstract}

Keywords: Mosque, Takya, Church, Schools, Badilis. $\square$ 